\title{
Optimal design and implementation of a drivetrain for an ultra-light electric vehicle
}

\section{Isabelle Hofman, Peter Sergeant and Alex Van den Bossche}

Department of Electrical Energy, Systems and Automation, Ghent University, Ghent, B-9000, Belgium

and

Flanders Make, The Strategic Research Centre for the Manufacturing Industry, Belgium Email: isabellehofman@gmail.com Email: peter.sergeant@ugent.be Email: alex.vandenBossche@ugent.be

\section{Selim Koroglu* and Selami Kesler}

Department of Electrical and Electronics Engineering, Pamukkale University, Denizli, 20070, Turkey Email: skoroglu@pau.edu.tr Email: skesler@pau.edu.tr ${ }^{*}$ Corresponding author

\begin{abstract}
This paper presents an integrated design of a drivetrain for a single-person ultra-light electric vehicle (ULEV). To calculate losses and efficiency of the inverter, the permanent magnet synchronous machines (PMSMs) and the gearbox, parameterised analytical models are used. For the gearbox - which has a single gear ratio - the studied parameters are the gear ratio, the number of stages, the number of teeth and the module of each spur gear combination. The novelty of the paper is that it learns how the total average efficiency and the total mass of the drivetrain depend on the gear ratio, on the number of stages in the gearbox, on the motor parameters and on the chosen several driving cycles including the new European driving cycle (NEDC). On the basis of the presented results, it is possible to choose the right configuration of power electronics, PMSM and gearbox in order to have a good trade-off between high efficiency and low mass.
\end{abstract}

Keywords: electric vehicles; driving cycle; gearbox; optimal design; permanent magnet machines.

Reference to this paper should be made as follows: Hofman, I., Sergeant, P., Van den Bossche, A., Koroglu, S. and Kesler, S. (2016) 'Optimal design and implementation of a drivetrain for an ultra-light electric vehicle', Int. J. Vehicle Design, Vol. 72, No. 3, pp.262-283. 
Biographical notes: Isabelle Hofman received her Master's degree in Electromechanical Engineering in 2010 from the University College of Ghent, Belgium. In 2010, she became a PhD Researcher in a project entitled Ecologic Low Budget Electric vehicle at Ghent University. Her research is in the field of electric drives for light electric vehicles.

Peter Sergeant received his MSc in Electromechanical Engineering in 2001, and the PhD in Engineering Sciences in 2006, both from Ghent University, Ghent, Belgium. Since 2012, he is an Associate Professor at Ghent University. His current research interests include numerical methods in combination with optimisation techniques to design non-linear electromagnetic systems, in particular, electrical machines for sustainable energy applications.

Alex Van den Bossche received his $\mathrm{MS}$ and the $\mathrm{PhD}$ in Electromechanical Engineering from Ghent University Belgium, in 1980 and 1990, respectively. He has worked there at the Electrical Energy Laboratory. Since 1993, he is a Professor at the same university in the same field. His research is in the field of electrical drives, power electronics on various converter types and passive components and magnetic materials. He is also interested in renewable energy conversion. He is an author of the book Inductors and Transformers for Power Electronics. He was a starter of two spin-off companies Invertor n.v. and Alenco n.v.

Selim Koroglu received his MSc in Electrical and Electronics Engineering from Pamukkale University, Turkey in 2002 and his $\mathrm{PhD}$ in Electrical Engineering from Yildiz Technical University, Turkey in 2010. Since 2011, he works as an Assistant Professor at Pamukkale University. His research interests include magnetic shielding, energy management, power systems and power quality.

Selami Kesler received his BSc, MSc and PhD in Electrical Engineering from Karadeniz Technical University, Turkey in 1991, 1998 and 2006, respectively. He joined Karadeniz Technical University in 1992 and worked as a Lecturer until 2004. He then joined the Department of Electrical Education, Pamukkale University, Denizli, Turkey, in 2004 as a Lecturer. Since 2011, he is an Assistant Professor at Pamukkale University. His fields of interest are power electronics, AC drives, dynamic analysis of the electrical machines, intelligent control techniques and advanced DSPs.

\section{Introduction}

Although a lot of research is done about electric vehicles (EV) (Chan et al., 2010; Chan and Wong, 2004; Ehsani et al., 2005), the major problem of commercial EVs today is the high cost and high mass of the energy storage. This often leads to a limited driving range and to a high investment cost. Santiago et al. (2012) give a market overview of EVs. Two market tendencies are shown. Firstly, there are EVs designed for commuting purposes with low battery weight and short range. Secondly, there are long-range EVs with high-capacity batteries. In this paper, we focus on the first market tendency: an EV for commuting purposes. This ultra-light electric vehicle (ULEV), mainly for commuting purposes in the city and suburbs, is a single-person EV with batteries. The car has three wheels: two driven and steering front wheels and one rear wheel. The maximum speed of the car is about $70 \mathrm{~km} / \mathrm{h}$ and a range of about $100 \mathrm{~km}$ has to be covered. From the 
comparison of batteries in Khaligh and Zhihao (2010), a Lithium-Polymer (LiPo) battery is found to be the best candidate for the ULEV.

To reduce the energy consumption, the vehicle should be ultra-light. Table 1 compares the specifications of three small commercial EVs. As these EVs are much smaller than a conventional passenger car, they can also be much lighter. However, the table shows that they all still have a rather high weight given the small dimensions, and a limited driving range in spite of the rather large battery weight. Apart from weight minimisation, another good technique to reduce the energy consumption is reducing the motor power. Werber et al. (2009) conclude that lower power EVs, corresponding to present economy cars, will be able to have smaller battery packs, range, mass and cost.

Table 1 Small commercial EVS

\begin{tabular}{lccc}
\hline Vehicle & Cree SAM & Tazzari zero & Renault Twizy 80 \\
\hline Description & Three-wheeler & Four-wheeler 2 places & Four-wheeler \\
& 2 front wheels & & 2 places $(1+1)$ \\
Motor & 2 places $(1+1)$ & & \\
& BLDC $15 \mathrm{~kW}$ & Asynchronous motor & Asynchronous motor \\
Drive & rear-wheel drive & $15 \mathrm{~kW}$ rear-wheel drive & $14 \mathrm{~kW}$ rear-wheel drive \\
Battery & Belt $(5.54: 1)$ & Automatic transmission & $\begin{array}{c}\text { Single-speed } \\
\text { transmission }\end{array}$ \\
Battery weight & Lead-Tin & Lithium-ion & Lithium-ion \\
Consumption & $168 \mathrm{~V}-3.53 \mathrm{kWh}$ & $220 \mathrm{~V}-12.3 \mathrm{kWh}$ & $220 \mathrm{~V}-6.1 \mathrm{kWh}$ \\
Top speed & $140 \mathrm{~kg}$ & $142 \mathrm{~kg}$ & $100 \mathrm{~kg}$ \\
Range & $5 \mathrm{kWh} / 100 \mathrm{~km}$ & $13.5 \mathrm{kWh} / 100 \mathrm{~km}$ & $6 \mathrm{kWh} / 100 \mathrm{~km}$ \\
Total weight & $85 \mathrm{~km} / \mathrm{h}$ & $100 \mathrm{~km} / \mathrm{h}$ & $80 \mathrm{~km} / \mathrm{h}$ \\
Dimensions $(1, \mathrm{~h}, \mathrm{~b})$ & $3160,1580,1550 \mathrm{~mm}$ & $2880,1425,1560 \mathrm{~mm}$ & $2337,1454,1234 \mathrm{~mm}$ \\
Price & 8500 euro +100 euro & 14,900 euro $+3900 \mathrm{euro}$ & 7690 euro +62 euro \\
& rent $/$ month for batteries & battery pack $150 \mathrm{~km}$ & rent $/ \mathrm{month} \mathrm{for} \mathrm{batteries}$ \\
Information & www.cree.ch & www.tazzari-zero.com & www.renault.be \\
\hline
\end{tabular}

The aim of the ULEV presented in this paper is to have a transportation method with less energy consumption than a commercial EV but nevertheless with a much higher top speed, higher comfort and more safety than a bicycle. To realise this, the size of the vehicle is low ( $2.2 \mathrm{~m}$ length), the total curb weight is minimised (100 kg including $11 \mathrm{~kg}$ batteries, which is much lower than the vehicles in Table 1), and a highly efficient and low-weight drivetrain is developed with a rather limited rated power $(2 \times 1.5 \mathrm{~kW})$.

For electric motor drives in EVs, a selection guide is presented in Xue et al. (2008) and Chau and $\mathrm{Li}$ (2014). The considered motors are induction motors (IMs), permanent magnet synchronous machines (PMSMs) and switched reluctance motors (SRMs). According to Xue et al. (2008), the PMSM has a higher efficiency compared to an 
IM and a SRM, which makes it a preferred choice when a large constant power range is not required. PM motors allow a great flexibility in design and can fit in limited spaces, which is very important for in-wheel motors. In Pellegrino et al. (2012), a comparison is made between a surface and an interior PM motor with equal size and cooling. The surface PM motor has higher PM losses at high speed, but these losses can be reduced by segmentation. In Tarimer and Ocak (2009), a comparison is done between inner and outer rotor PM machines with surface mounted magnets. The outer rotor PM machine is preferred for its lower total weight and cost and the ease of installation. Thus, in the ULEV drivetrain, an outer rotor PMSM with surface magnets is chosen.

The recommended control technique for PMSMs depends on the electromotive force (EMF) waveform (Ehsani et al., 2005). To maximise the efficiency and minimise the torque ripple, a machine with sinusoidal back EMF is suitable for a brushless AC control strategy. Such a control requires a precision rotor position sensor to control the sinusoidal phase current. For a machine with trapezoidal back EMF, it is recommended to implement a brushless DC (BLDC) control with trapezoidal phase current waveforms. Here, low-cost Hall sensors can be used (Liu et al., 2005). In Estima and Cardoso (2012), two electric drive systems are compared. The first one uses a traditional inverter with pulse width modulation (PWM), and the second one uses a bidirectional DC-DC converter, which supplies the inverter. The maximum efficiency of the first topology is achieved at high speeds, whereas for the second topology is reached at low speeds. Therefore, the PMSMs are controlled by the BLDC technique with a conventional inverter with PWM in the ULEV.

In literature, there is lack of papers that study an integrated design of a complete powertrain towards high efficiency and low total weight, i.e., that study the global effect on the drivetrain mass and efficiency of gearbox parameters, motor parameters and power electronics (PE) parameters. In Roy et al. (2014) and Wu et al. (2011), algorithms are presented for the simultaneous optimisation of the size and control strategy of hybrid EV (HEV) components over different driving cycles. Scaling factors are used to vary the size of each component. In Lei et al. (2014), a system level design is developed by using algorithms to optimise the efficiency of an electrical drive consisting of a motor and control system for a HEV. However, the authors do not take into account the PE and the mechanical transmission in the design optimisation of the drive systems.

In this paper, the complete drivetrain of the ULEV is studied, consisting of the motor and inverter, the gearbox and the driving cycle. Effect of transmission design is important on over all EV performance (Ren et al., 2009). Gearbox design optimisation reduces energy consumption for EV considerably that is discussed in used (Zhang et al., 2013). Moreover, not only the gear ratio is varied, but also a sub-optimisation is done to decide on the module and the teeth numbers of the spur gears. Also, single-stage and two-stage versions are taken into account, but note that there is always only one transmission ratio. For the motor, not only the size is modified, but also the pole pair number and slot number are studied as input parameters. For the inverter, the control algorithm with a variable PWM frequency is taken into account in the model. The novelty of this work is the study of these gearbox, motor and inverter parameters on the total efficiency of the drivetrain for several driving cycles, and for several configurations of the motor and gearbox. 


\section{Overview of the vehicle}

Most available EVs today use a transmission with differential, which takes a lot of space and weight, and also increases the friction losses. In the ULEV, each front wheel is driven by an inverter and an outer rotor PMSM connected to an in-wheel gearbox. Each front wheel has its own gearbox, motor and inverter. The separated drives result in a fault-tolerant vehicle, without requiring each motor or inverter to be fault tolerant: when one drivetrain fails, the vehicle is still able to move.

A schematic overview of the complete drivetrain is shown in Figure 1. The losses shown in Figure 1 are the losses in the battery $\left(P_{\text {bat }}\right)$, the losses in the PE in each inverter $\left(P_{P E}\right)$, the losses in each motor $\left(P_{M}\right)$ and the losses in each gearbox $\left(P_{G B}\right)$. In this paper, we used the word 'inverter' to denote both the controller, which creates the gate driver signals and the PE together. In the power flow diagram of Figure 1, the control parts of both inverters are not shown. The usage of a LiPo battery $(96 \mathrm{~V}, 20 \mathrm{Ah}$ and $11 \mathrm{~kg})$ guarantees a high energy density (energy $/ \mathrm{kg}$ ) and a good high temperature performance.

A more detailed overview of the drivetrain with BLDC control is given in Figure 2. The working principles of the BLDC control are explained in Ehsani et al. (2005).

Figure 1 Schematic overview of the drivetrain losses

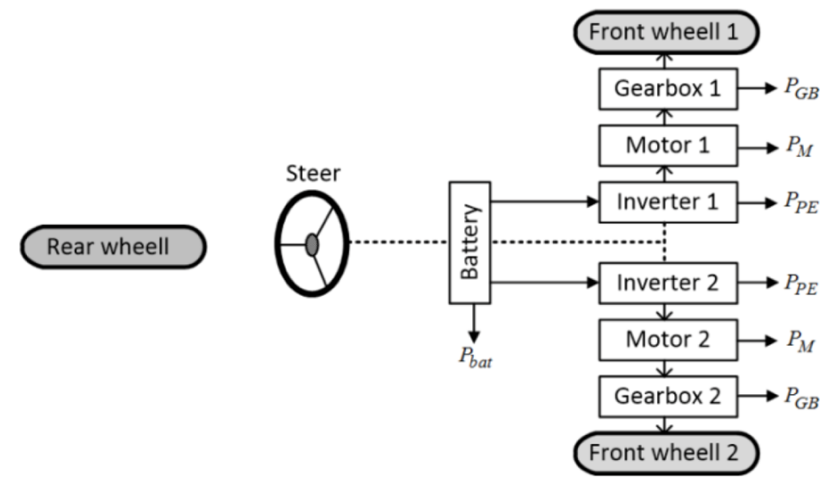

Figure 2 Overview of each drivetrain for each front wheel of an ULEV (see online version for colours)

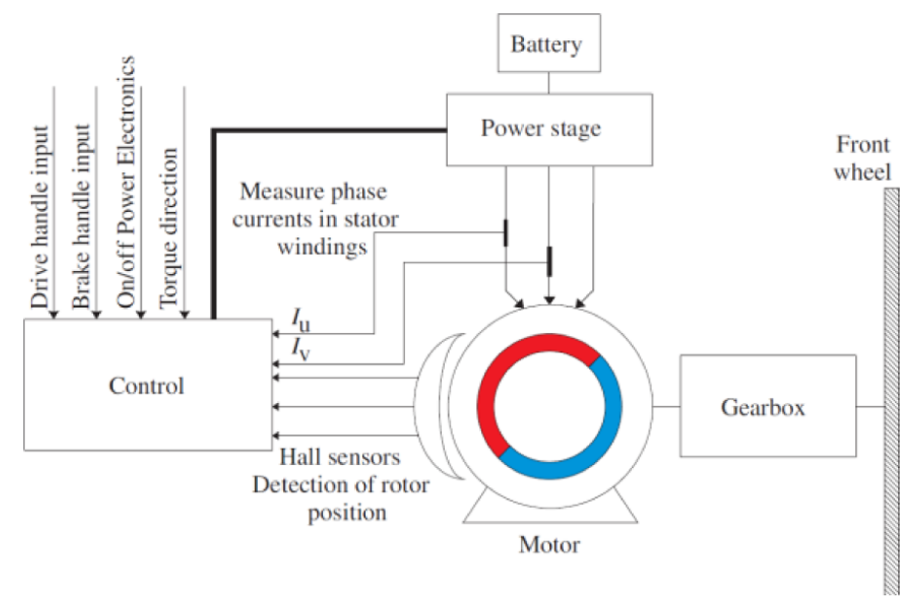


The in-wheel gearbox is a single-speed gearing; it does not have multiple gearing ratios. The gearbox has a threefold function. Firstly, it reduces the speed and increases the torque of the motor. Secondly, the aluminium flanges of the gearbox are used as a cooling pad and mounting plate for the motor. And finally, the most important function from economic point of view, the gearbox is also used as king pin for the suspension.

The chassis of the ULEV has to be light but nevertheless offer safety to the driver. Therefore, an aluminium space-frame chassis is designed in order to minimise the weight, to reduce stress concentrations, to guarantee the stiffness of the chassis and to protect the driver from a side impact: see Figure 3(a). The chassis is developed based on the five different finite element model (FEM) simulations:

- $\quad$ static forces on the vehicle, shown in Figure 3(a)

- forces during entering of the vehicle

- forces during a turn of $10 \mathrm{~m}$ radius at $50 \mathrm{~km} / \mathrm{h}$ : static forces plus centrifugal force.

- forces during braking of the vehicle

- forces during braking and turning of the vehicle at the same time, which will create the highest stress concentrations in the chassis.

Concerning the bodywork of the ULEV, low-cost polyester plates are combined with 3D-printed parts. The complex shaped nose of the ULEV consists of many puzzle pieces, 3D-printed in polylactid acid material and glued to each other. Figure 3(b) shows the bodywork and the nose of the ULEV. Also, drawing of the ULEV showing the chassis and drivetrain is depicted in Figure 3(c).

Figure 3 Prototype of the ULEV: (a) the static forces are shown on the chassis; (b) ULEV prototype and (c) drawing of the ULEV showing the chassis and drivetrain (see online version for colours)
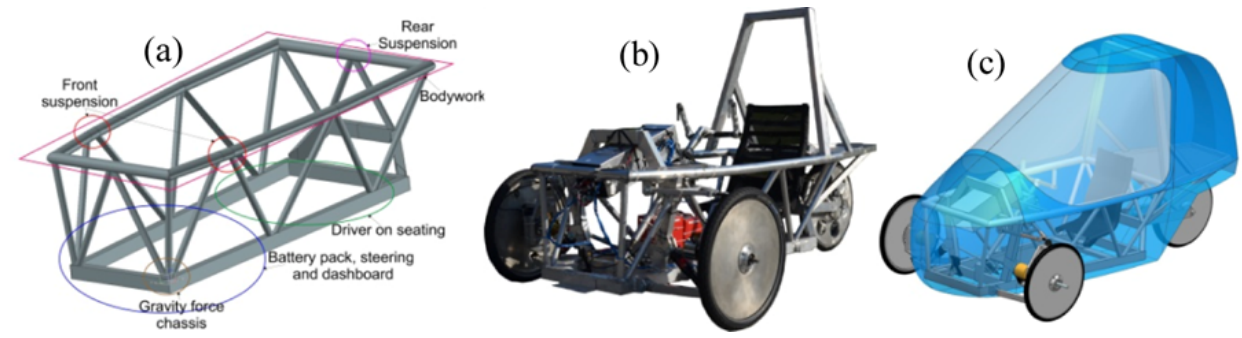

\section{Integrated design of the drivetrain}

The structure of the drivetrain model and the objective function for the integrated design is described in Hofman et al. (2015). The gearbox optimisation is a sub-optimisation in the objective function and is evaluated for different gear ratios. The input parameters of the objective function are: the number of pole pairs $\left(N_{p}\right)$, the number of stator slots $\left(N_{s}\right)$, the outer rotor radius of the motor $\left(r_{\text {rotor }}\right)$ and the gear ratio $(G R)$. The output parameters are the total average efficiency over a driving cycle and the total mass of the 
complete drivetrain. The objective function contains component models of the PE in the inverter, the motor and the gearbox. Two designs of the gearbox are implemented: a single-stage and a two-stage gearbox.

\section{Component models}

The three parameterised component models in the objective function are explained in the next sub-sections. An experimental validation of all analytical models is shown in Section 5. As the emphasis of this paper is not on detailed component models, only a brief overview of the models is given.

\subsection{Analytical model of the PE}

The analytical model for the PE calculates the loss $P_{P E}$ shown in Figure 1. It consists of the power loss in the DC link between the battery and the inverter $\left(P_{w D C}\right)$, the switching loss $\left(P_{s}\right)$ and conducting loss $\left(P_{r d s, o n}\right)$ of the MOSFETs on the printed circuit board, the power loss in the printed wires $\left(P_{p r w}\right)$, and the copper loss in the cables between the inverter and the motor $\left(P_{w}\right)$. Notice that all these loss terms are included for generality of the model, but some components may be negligibly small.

The power stage of the vehicle uses MOSFETS type IXTK140N20P. The conduction loss of this MOSFET can be computed based on the $R_{d s O N}$ of $36 \times 10^{-3} \Omega$ at temperature of $110^{\circ} \mathrm{C}$. The switching loss $\left(P_{s}\right)$ is:

$$
P_{S}=k \cdot V_{D C} \cdot Q_{r r} \cdot\left(\frac{I_{\mathrm{rms}}}{I_{F}}\right)^{0.5} \cdot f_{S}
$$

with $k$ a factor, equal to 3, that takes into account the load current during commutation and $Q_{r r}$ the reverse recovery charge of the intrinsic diode of the MOSFET. According to the datasheet of the MOSFET, $Q_{r r}$ is equal to $3.5 \times 10^{-6} \mathrm{C}$ at $25^{\circ} \mathrm{C}$. However, $Q_{r r}$ is known to be temperature dependent. Therefore, we have fitted $Q_{r r}$ with our measurements, resulting in the $Q_{r r}$ to be equal to $7.875 \times 10^{-6} \mathrm{C}$. The DC bus voltage $\left(V_{D C}\right)$ is $90 \mathrm{~V}$. Furthermore, $I_{r m s}$ is the rms value of the current waveform of the MOSFET, $I_{F}$ is the forward current of the diode, equal to $25 \mathrm{~A}$ (from datasheet) and $f_{s}$ is the switching frequency of the MOSFETs.

The total power loss for the PE in the inverter in the experimental test setup $\left(P_{P E}\right)$ is calculated by:

$$
P_{P E}=P_{\text {wireDC }}+P_{\text {printwire }}+P_{s}+P_{\text {rdoN }}+P_{\text {wire }} .
$$

\subsection{Analytical model of the motor}

The outer rotor PMSM model has the input parameters $N_{p}, N_{s}$ and $r_{\text {rotor }}$, with a range mentioned in Table 2. The parameter study is executed for 22 different outer rotor radii. As we want to study the whole drivetrain, the analytical model based on Sergeant and Bossche (2014), is implemented because it is fast and is valid for all outer rotor PMSMs with surface magnets in variable speed drives, but it has drawbacks: 
- a saturation flux density of $1.65 \mathrm{~T}$ is used to calculate the thickness of stator teeth and rotor yoke

- the losses consist only of the copper loss and the stator iron loss

- losses in the rotor yoke, magnets and bearings and additional stator iron losses by the leakage fluxes are neglected.

The power loss of one motor $\left(P_{M}\right)$ is the sum of the copper loss $\left(P_{c u}\right)$ and the stator iron loss $\left(P_{f e}\right)(3)$. The analytical model neglects other losses.

$$
P_{M}=P_{c u}+P_{f e} .
$$

As we want to study the drivetrain towards minimal weight, the total active mass of the motor $\left(m_{\text {totalMotor }}\right)(\mathrm{kg})$ is calculated as follows:

$$
m_{\text {totalmotor }}=m_{c u}+m_{f e}+m_{\text {mag }}+m_{\text {rotoriron }}
$$

with $m_{c u}$ the copper mass, $m_{f e}$ the stator iron mass, $m_{\text {mag }}$ the magnet mass and $m_{\text {rotoriron }}$ the rotor iron mass. The active mass of the motor only depends on the outer rotor radius, not on the gear ratio.

\begin{tabular}{|c|c|c|c|}
\hline Property & Symbol & Commercial PMSM & Analytical model PMSM \\
\hline \multicolumn{4}{|c|}{ General } \\
\hline Nominal speed & $N_{\text {nom }}$ & $4500 \mathrm{rpm}$ & Variable \\
\hline DC bus voltage & & $90 \mathrm{~V}$ & $90 \mathrm{~V}$ \\
\hline Nominal power & $P_{\text {nom }}$ & $1.5 \mathrm{~kW}$ & $1.5 \mathrm{~kW}$ \\
\hline \multicolumn{4}{|c|}{ Stator } \\
\hline Outer radius & $r_{s o}$ & $34.2 \mathrm{~mm}$ & Variable \\
\hline Copper fill factor & & 0.3 & 0.3 \\
\hline Tooth width & $w_{\text {toth }}$ & $3.9 \mathrm{~mm}$ & Variable \\
\hline Stack length & $L_{s}$ & $40 \mathrm{~mm}$ & $40 \mathrm{~mm}$ \\
\hline Numb. stator teeth & $N_{s}$ & 12 & 12 \\
\hline Turns per winding & $N_{w}$ & 10 & Variable \\
\hline \multicolumn{4}{|c|}{ Rotor } \\
\hline Outer radius & $r_{\text {rotor }}$ & $40 \mathrm{~mm}$ & $15-120 \mathrm{~mm}$ \\
\hline Number of pole pairs & $N_{p}$ & 7 & 7 \\
\hline Air gap thickness & $t_{a}$ & $0.55 \mathrm{~mm}$ & $0.19-1.50 \mathrm{~mm}$ \\
\hline Magnet-to-pole pitch ratio & $\alpha_{p}$ & 0.71 & 0.89 \\
\hline Magnet radial thickness & $t_{m}$ & $3.55 \mathrm{~mm}$ & $0.79-6.30 \mathrm{~mm}$ \\
\hline Magnet width & $w_{m}$ & $11 \mathrm{~mm}$ & Variable \\
\hline Magnet permeability & $\mu_{r}$ & $1.05 \mu 0$ & $1.05 \mu 0$ \\
\hline Magnet remanence & $B_{r}$ & $1.1 \mathrm{~T}$ & $1.1 \mathrm{~T}$ \\
\hline Yoke saturation flux density & $B_{t m}$ & $1.65 \mathrm{~T}$ & $1.65 \mathrm{~T}$ \\
\hline Additional axial yoke length & $L_{s e}$ & $20 \mathrm{~mm}$ & $15 \mathrm{~mm}$ \\
\hline Iron yoke thickness & $t_{r y}$ & $1.65 \mathrm{~mm}$ & Variable \\
\hline
\end{tabular}

Table 2 Parameters commercial PMSM and parameters analytical model PMSM 


\subsection{Analytical model of the gearbox}

The calculation of the gears in the gearbox model is based on Muhs et al. (2012). Firstly, the gear stresses and the gear strength were calculated. Secondly, based on the required wheel torque ( $25 \mathrm{~nm}$ for the considered ULEV), the appropriate moduli were selected. The required diameter of the shafts and the bearings is also computed based on Muhs et al. (2012). The gear material is hardened C45E and the shaft material is $42 \mathrm{CrMo} 4$. Two versions are developed: a single-stage and a two-stage version. We recall that there is only one transmission ratio between the two output shafts. The analytical model of the gearbox is a general model, valid for all spur gear gearboxes in terms of number of stages (one- or two-stages), module and gear ratios (number of teeth).

The efficiency computation of the gearbox models is based on experiments on the experimental two-stage gearbox, which is shown in Section 5.3. This was done because in the models described in literature (Petry-Johnson et al., 2008; Buckingham, 1949), the efficiency of the gearbox depends on many parameters (related to a.o. the way of lubrication and the type of oil) of which the value is hard to determine without experiments. The efficiency of the single-stage gearbox $\left(\eta_{1 \mathrm{~GB}}\right)$ is calculated depending on the efficiency of the two-stage gearbox $\left(\eta_{2 G B}\right)$ by $\eta_{1 G B}=\sqrt{\eta_{2 G B}}$. The efficiency correction per stage of the gearbox with other numbers of teeth is applied based on Ramamurti (2010):

$$
\eta_{\mathrm{corGB}}=1-\left(\frac{\mu}{\frac{\sin \phi}{\cos \phi}} \cdot\left(\frac{1}{z_{1}}+\frac{1}{z_{2}}\right)\right),
$$

where $\mu$ is a fixed friction coefficient, $\phi$ is the pressure angle of the gear (for a conventional spur gear $\left.\phi=20^{\circ}\right), z_{1}$ and $z_{2}$ are the numbers of teeth of the first and second gear, respectively.

The mass of the gearbox $\left(m_{G B}\right)$ is the sum of the mass of the spur gears $\left(m_{\text {gears }}\right)$, the mass of the bearings ( $m_{\text {bearings }}$ ), the mass of the shafts $\left(m_{\text {shafts }}\right)$ and the mass of the aluminium flanges ( $m_{\text {flanges }}$ ).

The gearbox model in the objective function contains a sub-optimisation to determine the number of teeth and the module of the spur gears. The analytical model of the gearbox is implemented for different GRs in order to choose the gearbox which has the lowest weight for each of the GRs. The investigated GRs for the single-stage gearbox are $1 / 2-1 / 7$ and for the two-stage gearbox $1 / 7-1 / 14$. The parameter study was also executed for a direct-drive combination, thus without the usage of a gearbox. Each of the motor and wheel gear combinations is able to transfer the required torque on the wheel of $25 \mathrm{~nm}$.

\section{Experimental setup and model validation}

Experimental setups: For validation of the analytical models, two experimental test setups were made, always in back-to-back configuration, and always with inverter supply of the PMSM:

- in the first test setup, the PMSM was mechanically coupled with the two-stage gearbox: PMSM (motor) - gearbox - gearbox - PMSM (generator); see Figure 4(a) 
- $\quad$ in the second test setup, the PMSM was directly coupled to the load PMSM, without gearbox: PMSM (motor) - PMSM (generator); see Figure 4(b).

In the test setups, the fundamental frequency of the inverter was varied between $50 \mathrm{~Hz}$ and $600 \mathrm{~Hz}$ in steps of $50 \mathrm{~Hz}$. The specifications of the two identical $1.5 \mathrm{~kW}$ PMSMs in the back-to-back setups are shown in Table 1 in Section 4.2. A Voltech PM6000 power analyser was used to measure the electrical power of the motor and the generator. A LiPo battery of $96 \mathrm{~V}$ and $20 \mathrm{Ah}$ was used to provide the power to the inverter. The two-stage gearbox consists for the first stage of a spur gear of 18 teeth at motor side combined with a spur gear of 40 teeth on the intermediate shaft, both with a module of $1 \mathrm{~mm}$. For the second stage, it consists of a spur gear of 16 teeth at the intermediate shaft combined with a spur gear of 50 teeth at the wheel side, both with a module of $1.5 \mathrm{~mm}$.

Figure 4 Test setups: (a) PMSMs and gearbox coupled back-to-back via the shaft of the gearbox and (b) PMSMs coupled back-to-back via the shaft of the motor (see online version for colours)

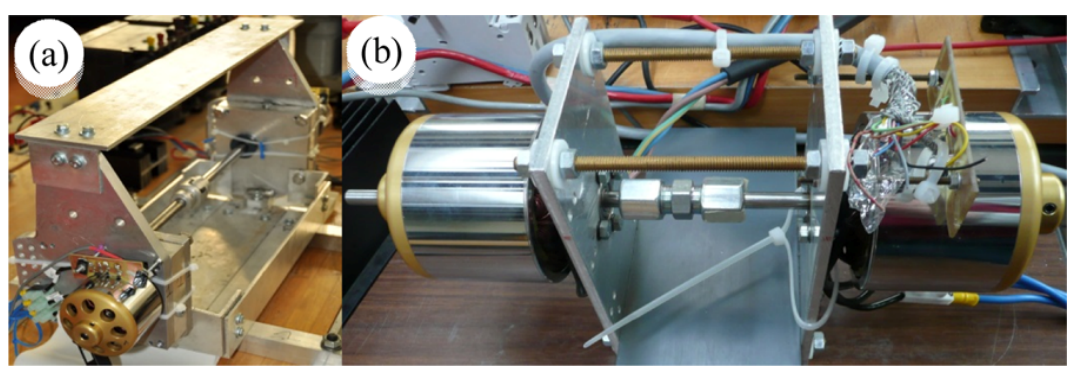

\subsection{Validation of the PE model with PWM}

The measured inverter efficiency map (using the second test setup) is shown in Figure 5(a), and the calculated inverter efficiency map (using the analytical model described in Section 4.1) is shown in Figure 5(b).

Figure 5 Efficiency maps of the inverter with PWM: (a) measured efficiency map. Average efficiency: $94.49 \%$, maximum efficiency: $99.42 \%$ and (b) calculated efficiency map. Average efficiency: $95.00 \%$, maximum efficiency: $98.71 \%$ (see online version for colours)
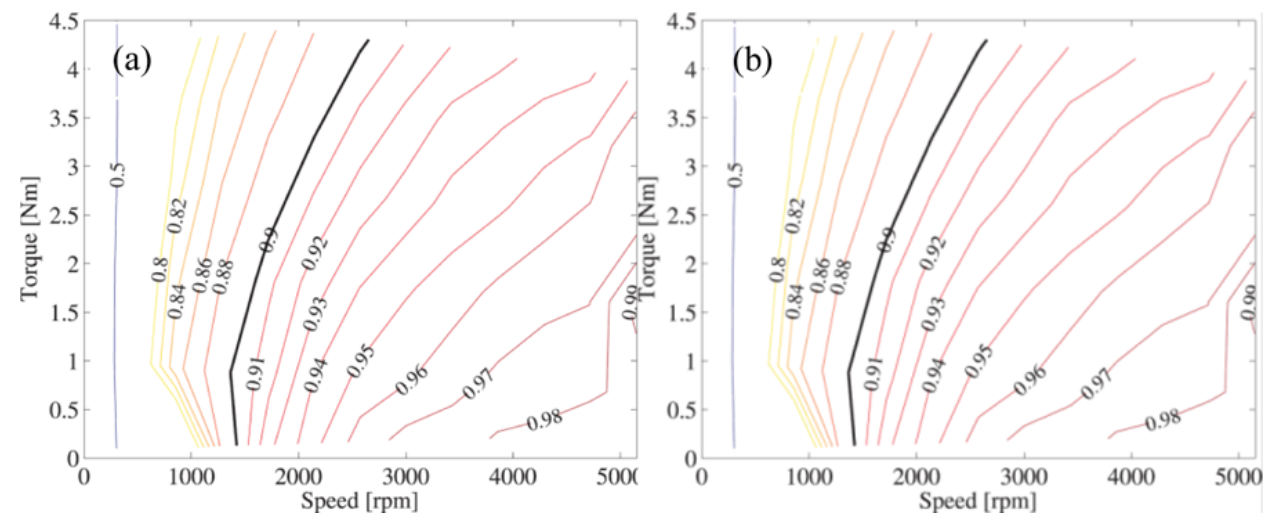
When comparing the measured efficiency maps with the calculated efficiency maps, equal trends can be observed, and also a good quantitative correspondence of the efficiencies. The figure caption mentions the average efficiency. This average is calculated over a speed range of $0.5 N_{\text {nom }}-N_{\text {nom }}$ and torque range of $0.5 T_{\text {nom }}-T_{\text {nom }}$.

\subsection{Validation of the motor model}

The efficiency map of the measured PMSM is obtained via the second test setup, and is shown in Figure 6(a). The analytical model of the PMSM results in the efficiency map of Figure 6(b). The maximum measured efficiency is reached at $2 / 5$ of the nominal speed and $4 / 7$ of the nominal torque.

Figure 6 (a) Measured efficiency map of the motor with PWM. Average efficiency: $87.56 \%$, maximum efficiency: $88.83 \%$ and (b) calculated efficiency map of the motor without PWM. Average efficiency: $90.38 \%$, maximum efficiency: $91.56 \%$ (see online version for colours)
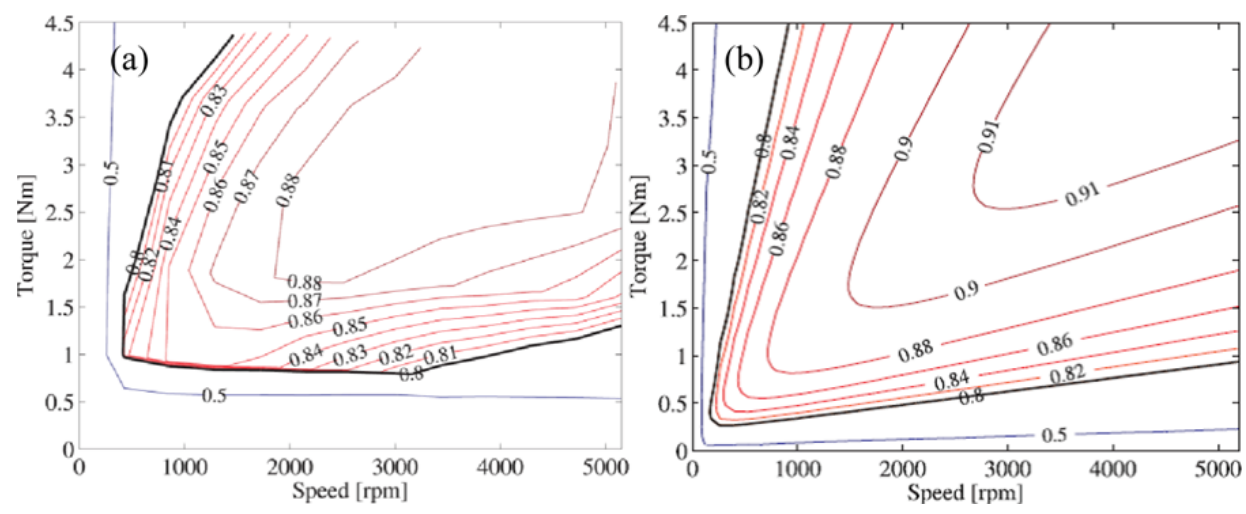

When comparing the calculated results with the measured results, there is an average difference of $2.82 \%$. This is mainly due to a number of drawbacks in the analytical model in Section 4.2: the analytical model does not take into account eddy-current losses in the rotor, PWM losses and bearing and windage losses. In Sergeant and Bossche (2014), a FEM was made taking into account much more loss terms.

Note that there is no constant power region in Figure 6, i.e., the maximum torque is available over the whole speed range. A higher speed than $5000 \mathrm{rpm}$ could be reached via flux weakening, but the maximum vehicle speed is limited to $20 \mathrm{~m} / \mathrm{s}$ (at $5200 \mathrm{rpm}$ ) for safety reasons. A higher torque than $4.5 \mathrm{~nm}$ for very low speed could also be obtained but it is not appropriate because of the limited rated torque of the gearbox.

\subsection{Validation of the two-stage gearbox}

The power loss of the two-stage gearbox $\left(P_{G B}\right)$ is measured as follows. In the first test setup (two motors with gearbox coupled back-to-back), the power loss of the motor plus gearbox $\left(P_{\mathrm{MGB}}\right)$ can be determined by $P_{\mathrm{MGB}}=\left(P_{\text {motMGB }}-P_{\text {genMGB }}\right) / 2$, with $P_{\text {motMGB }}$ the electrical input power of the motor and $P_{\text {genMGB }}$ the electrical output power of the generator when the motor is coupled with the gearbox. 
In the second test setup (two motors coupled back-to-back), the power loss of the motor $\left(P_{M}\right)$ can be determined by: $P_{M}=\left(P_{\text {mot }}-P_{\text {gen }}\right) / 2$, with $P_{\text {mot }}$ the electrical input power of the motor and $P_{\text {gen }}$ the electrical output power of the generator. The total loss of one gearbox $\left(P_{G B}\right)$ will be $P_{G B}=P_{\mathrm{MGB}}-P_{M}$. For calculation of the gearbox loss of other gear pair combinations of a two-stage or single-stage gearbox, the model takes into account the number of teeth (5).

On the basis of the power loss of the gearbox $\left(P_{G B}\right)$, the efficiency can be calculated. The resulting measured efficiency map of the two-stage gearbox is shown in Figure 7.

Figure 7 Measured efficiency map of the two-stage gearbox. Average efficiency: $96.03 \%$, maximum efficiency: $99.51 \%$. The crosses show the working points over NEDC (see online version for colours)

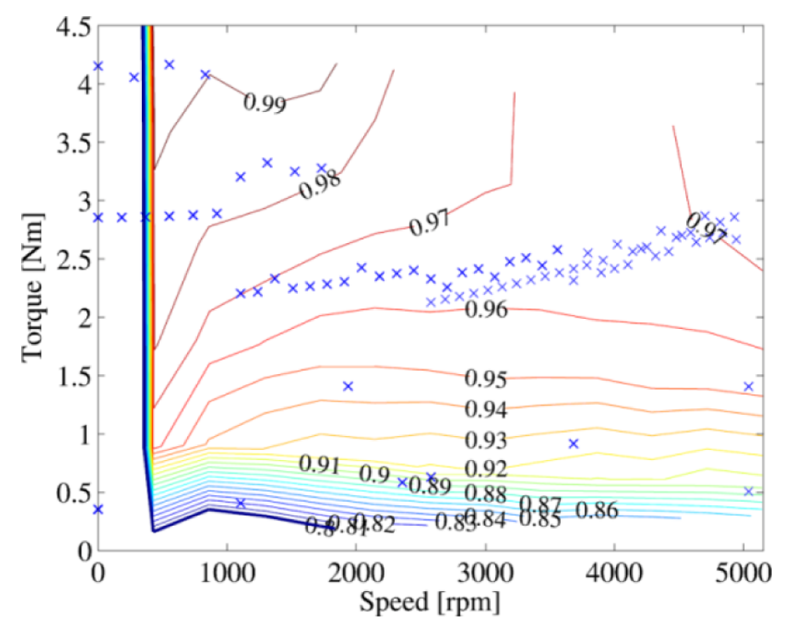

\section{Drivetrain evaluation over the NEDC}

The PMSM and gearbox are evaluated over new European driving cycle (NEDC) (Regulation No. 101, 2012). The test sequence of the NEDC is composed of two parts: an urban cycle made of four elementary ECE-15 urban cycles and an extra-urban cycle. NEDC is shown in Figure 8, but due to the maximum speed of $20 \mathrm{~m} / \mathrm{s}$ of the ULEV, NEDC is cut-off at that specific speed (see dashed line).

The instantaneous acceleration force over NEDC $\left(F_{\text {NEDC }}\right)$ is determined by the summation of the rolling force $\left(F_{\text {roll }}\right)$, the drag force $\left(F_{\text {drag }}\right)$ and the acceleration or deceleration force $\left(F_{a d}\right)$ :

$$
\begin{aligned}
P_{\mathrm{NEDC}}= & F_{\text {roll }}+F_{\mathrm{drag}}+F_{a d} \\
P_{\mathrm{NEDC}}= & \left(\mu_{\mathrm{roll}} \cdot m_{\text {tot,vehicle }} \cdot g\right) \\
& +\left(\frac{1}{2} \cdot C_{\mathrm{drag}} \cdot A_{\text {vehicle }} \cdot \rho_{\mathrm{air}} \cdot\left(v_{\mathrm{NEDC}}\right)^{2}\right) \\
& +\left(m_{\text {tot,vehicle }} \cdot \alpha_{\mathrm{NEDC}}\right)
\end{aligned}
$$


with $\mu_{\text {roll }}$ the rolling coefficient $(0.01), m_{\text {tot,vehicle }}$ the total mass of the vehicle plus driver $(200 \mathrm{~kg}), g$ the gravity constant, $C_{\text {drag }}$ the drag coefficient of the vehicle (0.3) determined via wind tunnel tests on a scale model, $A_{\text {vehicle }}$ the frontal surface of the vehicle $\left(0.9 \mathrm{~m}^{2}\right)$, $\rho_{\text {air }}$ the density of air $\left(1.2 \mathrm{~kg} / \mathrm{m}^{3}\right.$ at $\left.20^{\circ} \mathrm{C}\right), v_{\mathrm{NEDC}}$ is the instantaneous speed over NEDC and $\alpha_{N E D C}$ the instantaneous acceleration over NEDC.

Figure 8 New European driving cycle, the dashed line is the maximum speed of the ULEV. The vehicle speed is kept constant at $20 \mathrm{~m} / \mathrm{s}$ for each value of the driving cycle vehicle speed above $20 \mathrm{~m} / \mathrm{s}$. The duration of the driving cycle is unchanged. By consequence, the total distance of the driving cycle is reduced from $11.017 \mathrm{~km}$ to $10.189 \mathrm{~km}$ (see online version for colours)

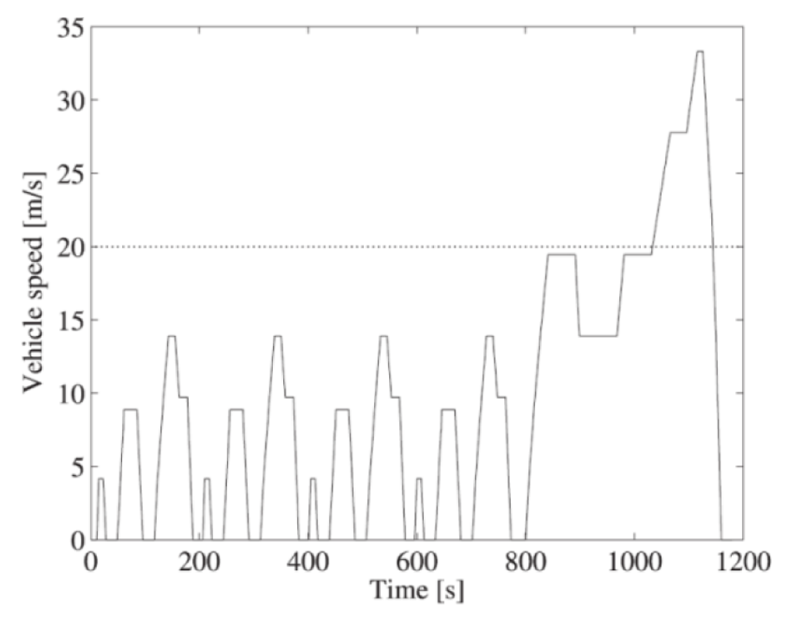

The theoretical energy needed to drive NEDC is:

$$
E_{\mathrm{NEDC}}=\int_{0}^{t_{\mathrm{NEDC}}} t_{\mathrm{NEDC}} \mathrm{d} t=\int_{0}^{t_{\mathrm{NEDC}}}\left(F_{\mathrm{NEDC}} \cdot v_{\mathrm{NEDC}}\right) \mathrm{d} t,
$$

where $t_{\mathrm{NEDC}}$ is the total time of the $N_{\mathrm{EDC}}$ and PNEDC is the instantaneous power over NEDC. The theoretical energy needed to drive NEDC is equal to $160.49 \mathrm{Wh}$ or $577.77 \times 10^{3} \mathrm{Ws}$.

\subsection{Calculations for the evaluation of the drivetrain over NEDC}

The total loss of the drivetrain $\left(P_{D T}\right)$ is the sum of the loss in the battery $\left(P_{\mathrm{bat}}\right)$, the loss in the two inverters $\left(P_{P E}\right)$, the loss in the two PMSMs $\left(P_{M}\right)$ and the loss in the two gearboxes $\left(P_{G B}\right)$ - see also Figure 1:

$$
P_{D T, \mathrm{NEDC}}=P_{\mathrm{bat}}+\left(P_{P E} \cdot 2\right)+\left(P_{M} \cdot 2\right)+\left(P_{G B} \cdot 2\right) .
$$

This drivetrain loss is evaluated in all working points over NEDC, indicated by crosses in Figure 7 . The total energy loss of the drivetrain over NEDC $\left(E_{D T, N E D C}\right)$ can be calculated by:

$$
E_{\mathrm{NEDC}}=\int_{0}^{t_{\mathrm{NEDC}}} P_{D T, \mathrm{NEDC}} \mathrm{d} t
$$

Now the total average efficiency of the complete drivetrain $\left(\eta_{D T, \mathrm{NEDC}}\right)$ can be calculated: 


$$
\mu_{D T, \mathrm{NEDC}}=\frac{E_{\mathrm{NEDC}}}{E_{\mathrm{NEDC}}+E_{D T, \mathrm{NEDC}}} .
$$

The total driving range of the drivetrain evaluated over NEDC depends on the total efficiency of the drivetrain $\left(\eta_{D T, \mathrm{NEDC}}\right)$, the theoretical energy needed to drive NEDC $\left(E_{\mathrm{NEDC}}\right)$ and the energy of the battery $E_{\mathrm{bat}}$ :

$$
X_{\mathrm{tot}, \mathrm{NEDC}}=\left(\frac{E_{\mathrm{bat}}}{\frac{E_{\mathrm{NEDC}}}{E_{D T, \mathrm{NEDC}}}}\right) \cdot X_{\mathrm{NEDC}} .
$$

\section{Study of mass and efficiency of the drivetrain as function of motor radius and gear ratio}

In Figure 9(a), the average efficiency over NEDC for a drivetrain with a single-stage gearbox is shown. A very important observation in Figure 9(a) is that with an increasing GR of the single-stage gearbox, the outer rotor radius should decrease to get a higher average efficiency of the drivetrain over NEDC. This is due to the dominant iron losses of the motor when a big outer rotor radius is selected. Figure 9(b) shows the total mass of the drivetrain with a single-stage gearbox. Here the same tendency is visible: for an increasing GR, the outer rotor radius should decrease to obtain a minimal weight of the total drivetrain.

Figure 9 Average efficiency and total mass of the drivetrain over NEDC for a drivetrain with a single-stage gearbox: (a) average efficiency over NEDC. The dash-dot line shows the high efficiency region that encloses combinations of GR and $r_{\text {rotor }}$ that yield the highest average efficiency and (b) total mass of the drivetrain (see online version for colours)
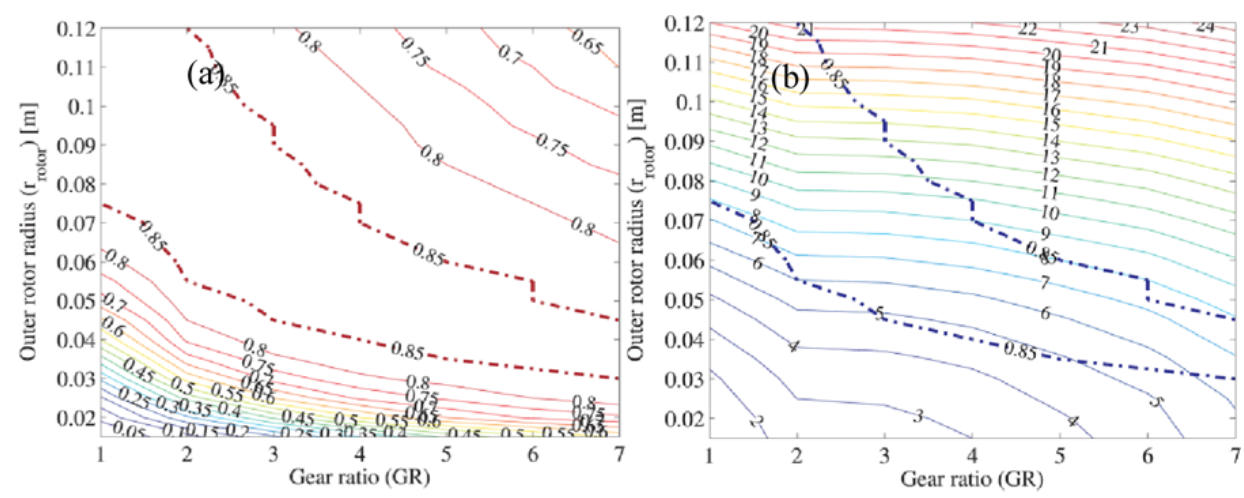

To have both a high average efficiency and a low total mass, it is clear from Figure 9 (b) that a high GR (1/3-1/7) should be combined with a small outer rotor radius $(0.055-0.030 \mathrm{~m})$. For each GR, a suitable combination with an outer rotor radius can be found in order to have a high average efficiency, see dash-dot line in Figure 9(a).

Furthermore in Figure 9, a comparison can be made between a direct-drive drivetrain and a single-stage gearbox drivetrain. For a fair comparison, we choose two configurations with almost the same average efficiency over NEDC $(\approx 85 \%)$ 
but different outer rotor radius of the motor: $r_{\text {rotor }}=0.075 \mathrm{~m}$ for direct-drive, vs. $r_{\text {rotor }}=0.030 \mathrm{~m}$ and $\mathrm{GR}=1 / 7$ for the geared drivetrain. The mass of the direct-drive drivetrain is equal to the mass of the motor, as there is no gearbox. Although there is no extra gearbox weight, the direct-drive drivetrain results in a higher total mass $(7.91 \mathrm{~kg})$ compared to a drivetrain with a single-stage gearbox $(6.48 \mathrm{~kg})$ and with the same drivetrain efficiency.

In Figure 10, all the solutions of a single-stage drivetrain analysed over NEDC are shown in function of the two cost terms: average efficiency and total weight of the drivetrain. There is not a single optimal solution: each solution on the Pareto front is optimal in terms of average efficiency and total mass of the drivetrain. Each solution on the Pareto front can be chosen as a compromise between efficiency and mass. It can be seen that an average efficiency of $90 \%$ is possible with a heavy drivetrain of $13 \mathrm{~kg}$, and that an average efficiency of $85 \%$ is possible with a drivetrain of about $5 \mathrm{~kg}$. Furthermore, the dot and the square marker show that the weight difference can be significant, for the same average efficiency: there is a weight difference of $1.74 \mathrm{~kg}$. An optimal choice between average efficiency and total weight of the drivetrain can be made. The details of the dot and the square marker shown in Figure 10 are given in Table 3.

Figure 10 Pareto front with average efficiency over NEDC vs. total weight for a drivetrain with a single-stage gearbox

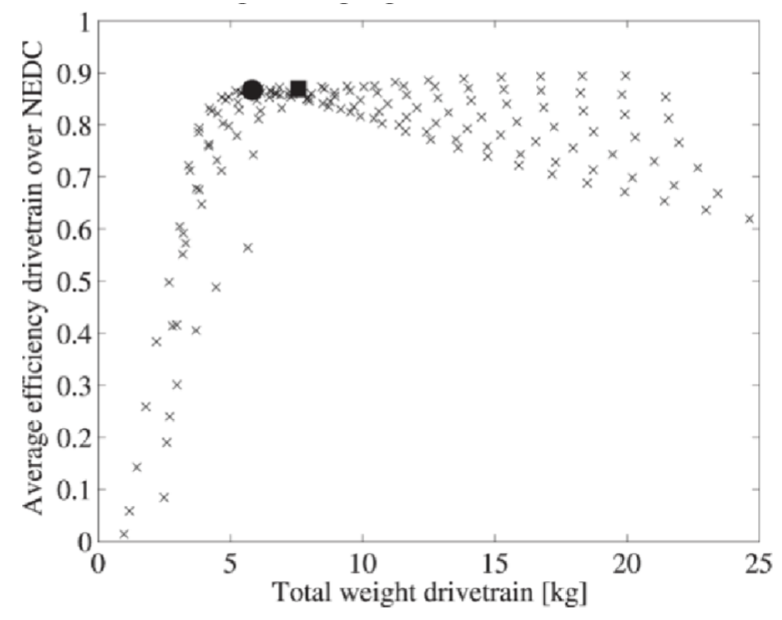

Table 3 The details of the dot and the square marker in the Figure 10

\begin{tabular}{lcc}
\hline Properties & $\begin{array}{c}\text { GR:1/4 (dot marker) } \\
r_{\text {rotor }}=0.050 \mathrm{~m}\end{array}$ & $\begin{array}{c}\text { GR: } 1 / 2(\text { square marker }) \\
r_{\text {rotor }}=0.065 \mathrm{~m}\end{array}$ \\
\hline Av. total eff. & $86.70 \%$ & $86.96 \%$ \\
Driving range & $98.08 \mathrm{~km}$ & $98.37 \mathrm{~km}$ \\
Total mass & $5.83 \mathrm{~kg}$ & $7.57 \mathrm{~kg}$ \\
Mass 1 GB & $1.37 \mathrm{~kg}$ & $1.12 \mathrm{~kg}$ \\
Mass 1 motor & $1.55 \mathrm{~kg}$ & $2.67 \mathrm{~kg}$ \\
\hline
\end{tabular}




\section{Study comparison of single- and two-stage gearbox}

In Figure 11, the average efficiency over the NEDC for a single-stage and two-stage gearbox drivetrain in function of the gear ratio and outer rotor radius of the motor is shown. Figure 12 shows the total mass in function of the same parameters. The single-stage gearbox drivetrain can have gear ratios between $1 / 2$ and 1/7; the two-stage gearbox drivetrain can have gear ratios between $1 / 7$ and $1 / 14$. At the gear ratio of $1 / 7$, a discontinuity is visible in both figures. This is the transition point between a single-stage and a two-stage gearbox. With an increasing GR, evidently, the outer rotor radius should decrease to get a higher average efficiency over NEDC.

Figure 11 Average efficiency over NEDC of a complete drivetrain in function of the GR and $r_{\text {rotor }}$ of the motor. The dash-dot line shows the region that encloses combinations of GR and $r_{\text {rotor }}$ that yield the highest average efficiency. The discontinuity at the GR of $1 / 7$ (dashed line) is the transition point between a single-stage and a two-stage gearbox drivetrain (see online version for colours)

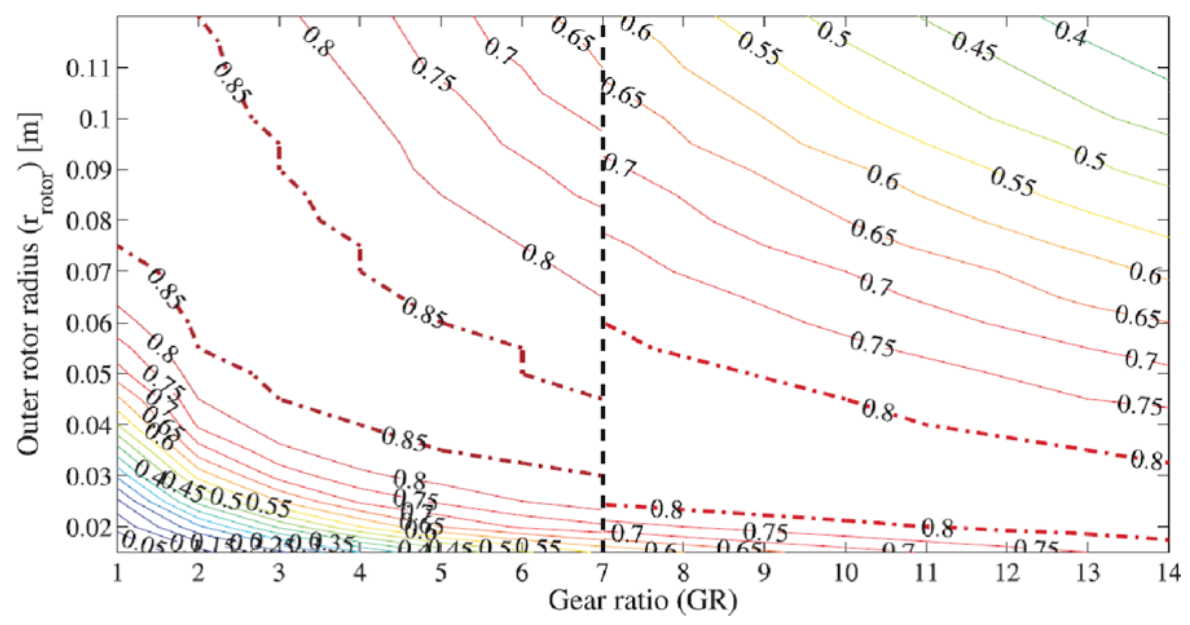

Compared to a drivetrain with a single-stage gearbox, the highest total average efficiency of a drivetrain with a two-stage gearbox (GR: 1/7) is 1.68\% lower. From Figures 11 and 12 , it is clear that a high efficiency with a two-stage gearbox drivetrain can be obtained with all the considered gear ratios $(1 / 7$ and $1 / 14)$ and a motor that is smaller than for a single-stage gearbox drivetrain. Considering the solution with the highest efficiency for each gear ratio for a two-stage gearbox drivetrain, the lowest mass is obtained for a gear ratio between $1 / 10$ and $1 / 14$.

The Pareto front of Figure 13 shows the average efficiency vs. the total weight for a drivetrain with a two-stage gearbox. The maximum average efficiency is obtained for a drivetrain with a minimal total weight. The detailed results of the dot and the square marker shown in Figure 13 are depicted in Table 4.

The conclusion of the parameter study for a GR of $1 / 7$ and $r_{\text {rotor }}$ of $0.040 \mathrm{~m}$ is that a drivetrain with a single-stage gearbox has a higher average efficiency over NEDC $(85.90 \%)$ compared to the one with a two-stage gearbox $(84.22 \%)$. This has also impact on the driving range, $2 \mathrm{~km}$ more for the single-stage gearbox. On the other hand, the total mass of the complete drivetrain with a single-stage gearbox is higher $(7.36 \mathrm{~kg})$ than for 
the one with a two-stage gearbox $(5.59 \mathrm{~kg})$. The difference in the results of the total mass is due to the mass of the gearbox which is higher for a drivetrain with a single-stage gearbox (mass one gearbox: $2.70 \mathrm{~kg}$ ) than for the one with a two-stage gearbox (mass one gearbox: $1.82 \mathrm{~kg}$ ). The conclusion is that a single-stage gearbox has $1-2 \%$ higher efficiency for the same GR (1/7) compared to a two-stage gearbox. On the other hand, the two-stage gearbox is lighter. If the gear ratio can be chosen, the lightest solution is obtained with a two-stage gearbox (GR: 1/10). With a single-stage gearbox, the lightest solution is obtained at a GR of $1 / 4$. In the experimental setup, a two-stage gearbox with GR 1/7 was chosen, and a motor of $0.040 \mathrm{~m}$ radius. This combination has the highest efficiency.

Figure 12 Total mass $(\mathrm{kg})$ of a complete drivetrain in function of the GR and $r_{\text {rotor }}$ of the motor. The dash-dot line shows the region that encloses combinations with the highest average efficiency according to Figure 11 (see online version for colours)

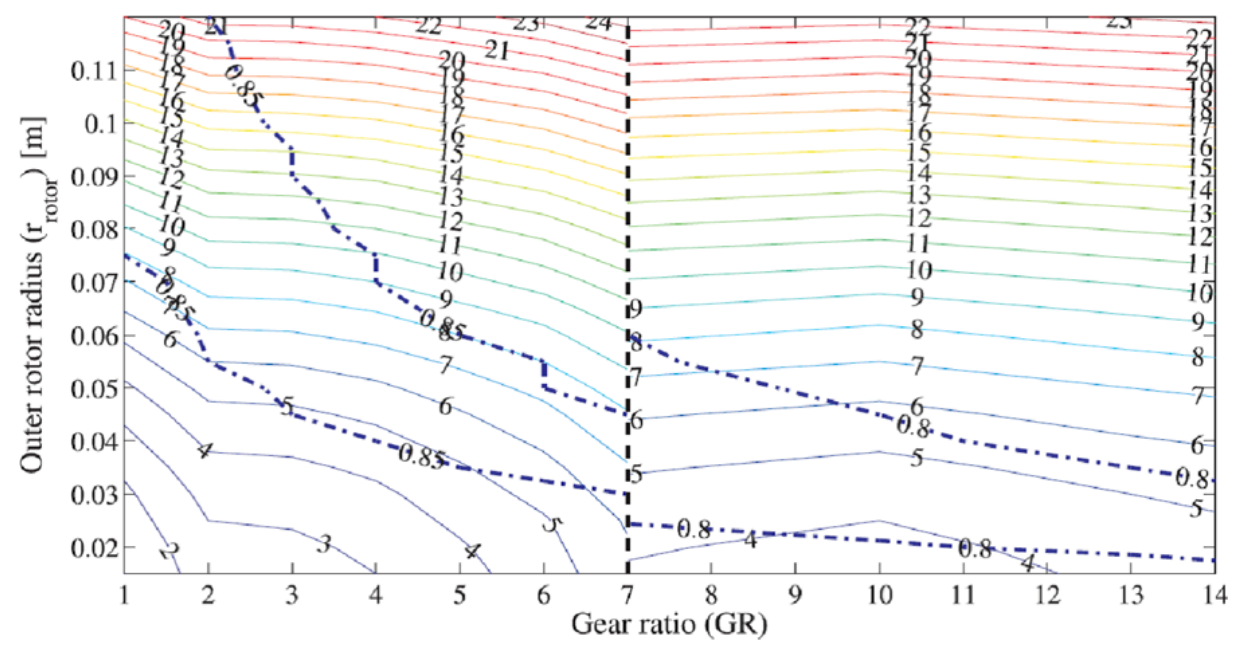

Figure 13 Pareto front with efficiency vs. weight for a drivetrain with a two-stage gearbox

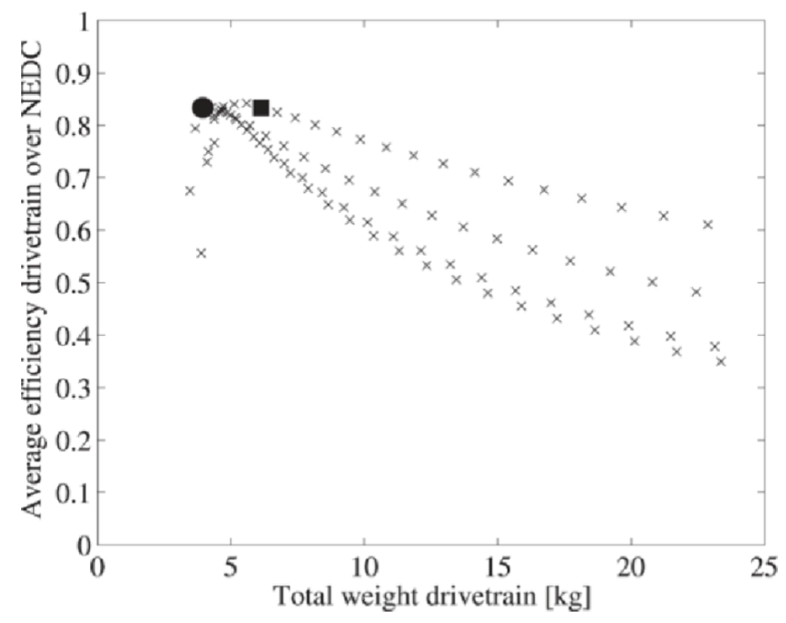


Table 4 The details of the dot and the square marker in the Figure 13

\begin{tabular}{lcc}
\hline Property & $\begin{array}{c}\text { GR: } 1 / 10(\text { dot marker }) \\
r_{\text {rotor }}=0.025 \mathrm{~m}\end{array}$ & $\begin{array}{c}\text { GR: } 1 / 7 \text { (square marker }) \\
r_{\text {rotor }}=0.045 \mathrm{~m}\end{array}$ \\
\hline Av. total eff. & $83.36 \%$ & $83.35 \%$ \\
Driving range & $94.30 \mathrm{~km}$ & $94.29 \mathrm{~km}$ \\
Total mass & $3.95 \mathrm{~kg}$ & $6.13 \mathrm{~kg}$ \\
Mass 1 GB & $1.61 \mathrm{~kg}$ & $1.82 \mathrm{~kg}$ \\
Mass 1 motor & $0.37 \mathrm{~kg}$ & $1.25 \mathrm{~kg}$ \\
\hline
\end{tabular}

\section{Integrated design for other driving cycles}

Apart from the NEDC, in this section, two other driving cycles are used to study the complete drivetrain. The used driving cycles are Federal Test Procedure (FTP 75) and New York City Cycle (NYCC) (Barlow et al., 2009; Courtois, 2013). Both cycles are transient driving cycles. This means that the cycles involve many speed variations which are typical for on-road driving conditions. NYCC, shown in Figure 14(a), features low speed stop-and-go traffic conditions in New York. FTP 75 cycle, shown in Figure 14(b), combines urban driving (with frequent stops) with highway driving. The parameters of the driving cycles are shown in Table 5.

Figure 14 (a) New York City Cycle (NYCC) and (b) Federal Test Procedure (FTP 75), the dashed line is the maximum speed of the ULEV. The vehicle speed is kept constant at $20 \mathrm{~m} / \mathrm{s}$ for each value of the driving cycle vehicle speed above $20 \mathrm{~m} / \mathrm{s}$. The duration of the driving cycle is unchanged. By consequence, the total distance of the driving cycle is reduced from $17.787 \mathrm{~km}$ to $17.078 \mathrm{~km}$
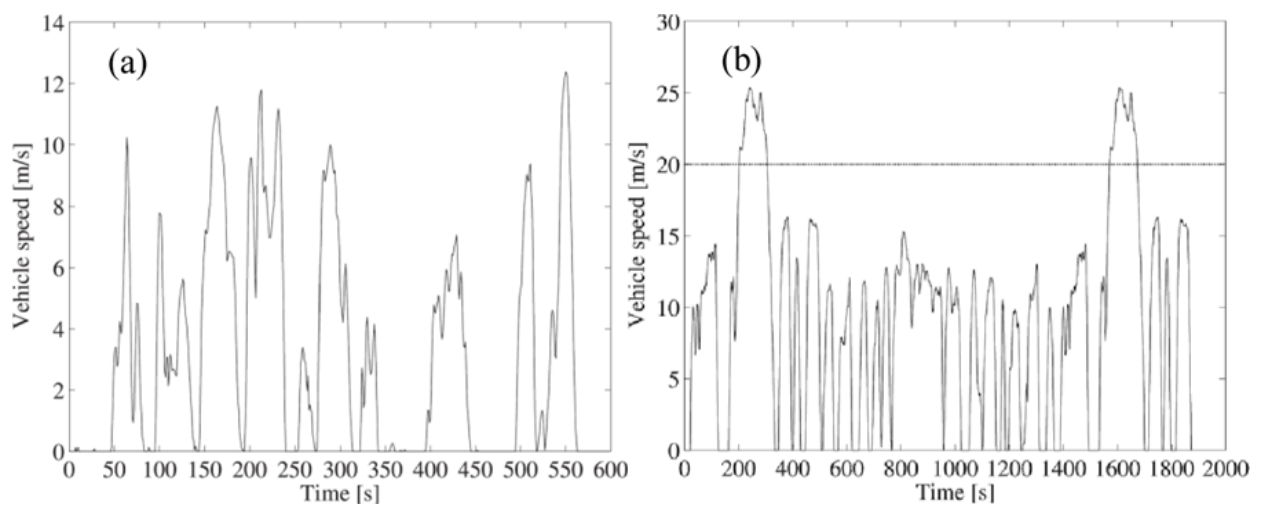

Table 5 Parameters driving cycles for evaluation drivetrain

\begin{tabular}{lccc}
\hline Property & NEDC & NYCC & FTP 75 \\
\hline Av. speed & $31.1 \mathrm{~km} / \mathrm{h}$ & $11.5 \mathrm{~km} / \mathrm{h}$ & $32.8 \mathrm{~km} / \mathrm{h}$ \\
Max. speed & $72 \mathrm{~km} / \mathrm{h}$ & $44.45 \mathrm{~km} / \mathrm{h}$ & $72 \mathrm{~km} / \mathrm{h}$ \\
Distance & $10.189 \mathrm{~km}$ & $1.903 \mathrm{~km}$ & $17.078 \mathrm{~km}$ \\
Duration & $1180 \mathrm{~s}$ & $598 \mathrm{~s}$ & $1874 \mathrm{~s}$ \\
\hline
\end{tabular}


In Figure 15, the average efficiency over NYCC for a single-stage and two-stage gearbox drivetrain in function of the gear ratio and outer rotor radius of the motor is shown. Again, the single-stage gearbox drivetrain can have gear ratios between 1/2 and 1/7; the two-stage gearbox drivetrain can have gear ratios between 1/7 and 1/14. Comparing the results of Figure 15 with the results over NEDC for a drivetrain with single-stage gearbox and two-stage gearbox, respectively (Figure 11), the highest average efficiency in case of NYCC is decreased by $20.06 \%$ and $18.22 \%$, respectively. This is due to the different driving pattern of NYCC compared to NEDC, where the vehicle has to start and stop frequently. The mass is given in Figure 12.

Figure 15 Average efficiency over NYCC of a complete drivetrain in function of the GR and $r_{\text {rotor }}$ of the motor. The dash-dot line shows the region with the highest average efficiency (see online version for colours)

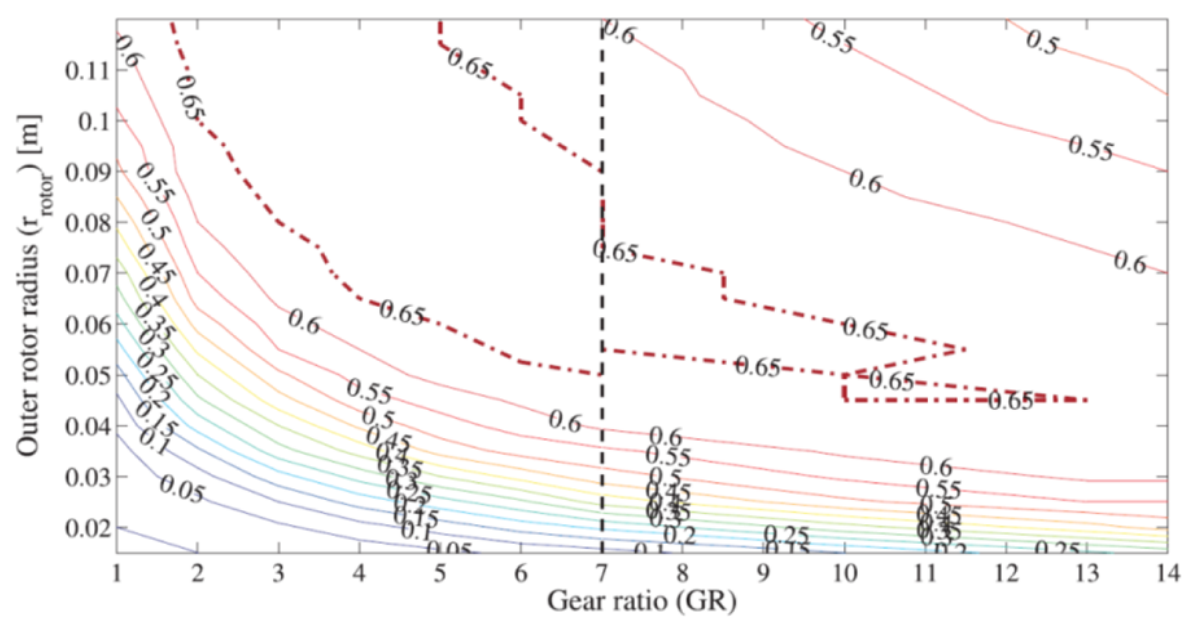

The average efficiency over FTP for a single-stage and two-stage gearbox drivetrain in function of the gear ratio and outer rotor radius of the motor are shown in Figure 16. Compared to the results over NEDC for a drivetrain with single-stage gearbox and two-stage gearbox, respectively (Figure 11), the highest average efficiency in case of FTP slightly decreases by $1.11 \%$ and $1.55 \%$, respectively.

Table 6 shows the results from the evaluation over the three driving cycles for a combination with on the one hand a single-stage gearbox drivetrain, and on the other hand a two-stage gearbox drivetrain. The NEDC and FTP driving cycle result in a similar efficiency.

Table 6 Results of the total drivetrain over three driving cycles

\begin{tabular}{lcccccc}
\hline & \multicolumn{3}{c}{ Single-stage, GR:1/5, $r_{\text {rotor }}: 0.050 \mathrm{~m}$} & \multicolumn{3}{c}{ Two-stage, GR:1/7, $r_{\text {rotor }}: 0.040 \mathrm{~m}$} \\
\cline { 2 - 7 } & NEDC & NYCC & FTPn75 & NEDC & NYCC & FTPn75 \\
\hline Av. total eff. & $86.43 \%$ & $62.30 \%$ & $85.46 \%$ & $84.22 \%$ & $60.54 \%$ & $83.31 \%$ \\
Driving range & $97.77 \mathrm{~km}$ & $262.00 \mathrm{~km}$ & $111.97 \mathrm{~km}$ & $95.27 \mathrm{~km}$ & $254.60 \mathrm{~km}$ & $109.16 \mathrm{~km}$ \\
Total mass & \multicolumn{3}{c}{$6.55 \mathrm{~kg}$} & & & $5.59 \mathrm{~kg}$ \\
\hline
\end{tabular}


Figure 16 Average efficiency over FTP of a complete drivetrain in function of the GR and $r_{\text {rotor }}$ of the motor. The dash-dot line shows the region with the highest average efficiency. The discontinuity at GR =1/7 (dashed line) is the transition point between a single-stage and a two-stage gearbox drivetrain (see online version for colours)

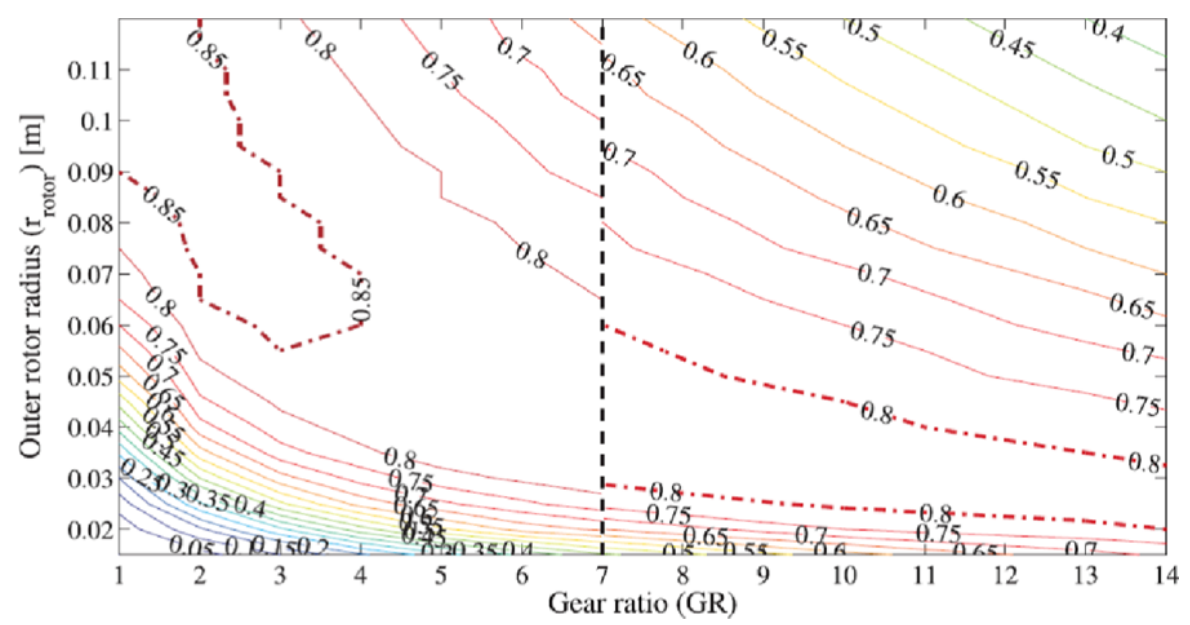

However, when comparing the NEDC and FTP with the NYCC, the average efficiency of the complete drivetrain is strongly reduced (more than 30\% for the single-stage gearbox drivetrain and more than $20 \%$ for the two-stage gearbox drivetrain). Also remarkable is that the highest average efficiency over NYCC is obtained with a motor of almost double radius compared to NEDC and FTP driving cycle. The reason is that NYCC demands a high-acceleration force of the vehicle, which results in higher motor losses. It is concluded that selecting a good combination of GR and outer rotor radius depends strongly on the driving cycle.

\section{Conclusion}

Three parameterised analytical models are developed to evaluate a complete drivetrain: a motor model, a gearbox model and a PE model. The studied parameters in the motor model, which are general for outer rotor PMSMs, are: the outer rotor radius, the number of pole pairs and the number of stator slots. However, other parameters could also be investigated with this model, e.g., stack length, magnet thickness and tooth width. The analytical model of the gearbox is general for all spur gear gearboxes. Single- and two-stage gearbox versions are taken into account. The gear ratio is varied and a sub-optimisation is done to decide on the module and the teeth numbers of the spur gears. The third model is the PE model that computes switching and conduction losses in the inverter with PWM. Each analytical model is validated via experiments. From measurements, it is clear that the analytical models have the same tendencies as the measured results. Therefore, the analytical models are useful for designing a good drivetrain.

An integrated design of a complete drivetrain is presented by using these parameterised analytical models. The goals of this integrated design are to obtain: 
- high efficiency over a driving cycle

- a low total weight of the drivetrain for an ULEV.

From the Pareto fronts, an optimal choice in average efficiency vs. total weight of the drivetrain can be made. This method can be applied to other EV.

For the same wheel torque, the same gear ratio and the same outer rotor radius, a drivetrain with a single-stage gearbox has a higher average efficiency over the driving cycles compared to the one with a two-stage gearbox. On the other hand, the total mass of a drivetrain with a single-stage gearbox is higher than the one with two-stage gearbox (1.77 kg higher for GR: $1 / 7, r_{\text {rotor }}: 0.040 \mathrm{~m}$ ).

Parameter studies for a complete drivetrain for three different driving cycles (NEDC, FTP and NYCC) are evaluated. When the drivetrain is used over NYCC, which demands high-acceleration forces and many stop-and-go situations, the optimal outer rotor radius of the motor must be almost doubled compared to NEDC, in order to have a high average efficiency over the driving cycle.

\section{References}

Barlow, T.J., Latham, S., McCrae, I.S. and Boulter, P.G. (2009) PPR354. In a Reference Book of Driving Cycles for Use in the Measurement of Road Vehicle Emissions, TRL.

Buckingham E. (1949) Analytical Mechanics of Gears, McGraw-Hill, USA.

Chan, C.C. and Wong, Y.S. (2004) 'Electric vehicles charge forward', IEEE Power Energy Magazine, Vol. 2, No. 6, November, pp.24-33.

Chan, C.C., Bouscayrol, A. and Chen, K. (2010) 'Electric, hybrid and fuel-cell vehicles: architectures and modelling', IEEE Transactions on Vehicular Technology, Vol. 59, No. 2, February, pp.589-598.

Chau, K.T. and Li, W. (2014) 'Overview of electric machines for electric and hybrid', International Journal of Vehicle Design, Vol. 64, No. 1, pp 46-71.

Courtois W. (2013) Dynamometer Drive Schedules, http://www.epa.gov/dynamometer.htm, 20 August.

Ehsani, M., Gao, Y., Gays, S.E. and Emadi, A. (2005) Modern Electric, Hybrid Electric, and Fuel Cell Vehicle: Fundamentals, Theory, and Design, CRC, Boca Raton, FL.

Estima, J.O. and Cardoso, A.J.M. (2012) 'Efficiency analysis of drive train topologies applied to electric/hybrid vehicles', IEEE Transactions on Vehicular Technology, Vol. 61, No. 3, March, pp.1021-1031.

Hofman, I., Sergeant, P., Bossche, A.V.d., Koroglu, S. and Kesler, S. (2015) 'Integrated model of power electronics, electric motor, and gearbox for a light EV', Journal of Power Electronics, Vol. 15, No. 6, November, pp.1640-1653.

Khaligh, A. and Zhihao, L. (2010) 'Battery, ultracapacitor, fuel cell, and hybrid energy storage systems for electric, hybrid electric, fuel cell, and plug-in hybrid electric vehicles: state of the art', IEEE Transactions on Vehicular Technology, Vol. 59, No. 6, July, pp.2806-2814.

Lei, G., Wang, T., Guo, Y., Zhu, J. and Wang, S. (2014) 'System level design optimization methods for electrical drive systems - deterministic approach', IEEE Transactions on Industrial Electronics, Vol. 61, No. 12, December, pp.6591-6602.

Liu, Y., Zhu, Z.Q. and Howe, D. (2005) 'Direct torque control of brushless DC drives with reduced torque ripple', IEEE Transactions on Industrial Applications, Vol. 41, No. 2, March-April, pp.599-608. 
Muhs, D., Wittel, H., Becker, M., Jannasch, D. and Voßiek, J. (2012) Uitwendige cilindrische tandwielen. In Roloff/Matek machine- onderdelen, 4th ed., Sdu Uitgevers, Den Haag, Netherlands, Chapter 21, pp.656-700.

Pellegrino, G., Vagati, A., Guglielmi, P. and Boazzo, B. (2012) 'Performance comparison between surface-mounted and interior PM motor drives for electric vehicle application', IEEE Transactions on Industrial Electronics, Vol. 59, No. 2, February, pp.803-811.

Petry-Johnson, T.T., Kahraman, A., Anderson, N.E. and Chase, D.R. (2008) 'An experimental investigation of spur gear efficiency', Journal of Mechanical Design, Vol. 130, No. 6, p.062601.

Ramamurti, V. (2010) 'Efficiency of gears', Mechanics of Machines, Narosa Publishing House, New Delhi.

Regulation No. 101 (2012) 'Regulation No 101 of the Economic Commission for Europe of the United Nations (UN/ECE)', Official Journal L 138, Vol. 2012, pp.0001-0077.

Ren, Q., Crolla, D.A. and Morris, A. (2009) 'Effect of transmission design on electric vehicle (EV) performance', The 5th IEEE Vehicle Power and Propulsion Conference (VPPC'09), 7-11 September, Dearborn, MI, pp.1260-1265.

Roy, H.K., McGordon, A. and Jennings, P.A. (2014) 'A generalized powertrain design optimization methodology to reduce fuel economy variability in hybrid electric vehicles', IEEE Transactions on Vehicular Technology, Vol. 63, No. 3, March, pp.1055-1070.

Santiago, J.D., Bernhoff, H., Ekergrd, B., Eriksson, S., Ferhatovic, S., Waters, R. and Leijon, M. (2012) 'Electrical motor drivelines in commercial all-electric vehicles: a review', IEEE Transactions on Vehicular Technology, Vol. 61, No. 2, February, pp.475-484.

Sergeant, P. and Bossche, A.V.d. (2014) 'Influence of the amount of permanent magnet material in fractional-slot permanent magnet synchronous machines', IEEE Transactions on Industrial Electronics, Vol. 61, No. 9, September, pp.4979-4989.

Tarimer, I. and Ocak, C. (2009) 'Performance comparision of internal and external rotor structured wind generators mounted from same permanent magnets on same geometry', Elektronika Ir Elektrotechnika, Vol. 92, No. 4, pp.65-70.

Werber, M., Fischer, M. and Schwartz, P. (2009) 'Batteries: lower cost than gasoline?', Energy Policy, Vol. 37, No. 7, July, pp.2465-2468.

Wu, L., Wang, Y., Yuan, X. and Chen, Z. (2011) 'Multiobjective optimization of HEV fuel economy and emissions using the self- adaptive differential evolution algorithm', IEEE Transactions on Vehicular Technology, Vol. 60, No. 6, July, pp.2458-2470.

Xue, X.D., Cheng, K.W.E. and Cheung, N.C. (2008) 'Selection of electric motor drives for electric vehicles' AUPEC '08 Power Engineering Conference, December, Sydney, Australia, pp.1-6.

Zhang, Z., Zuo, C., Hao, W., Zuo, Y., Zhao, X.L. and Zhang, M. (2013) 'Three-speed transmission system for purely electric vehicles', International Journal of Automotive Technology, Vol. 14, No. 5, pp.773-778. 